\title{
Impact of the COVID-19 pandemic on global health research training and education
}

\author{
Lifang Hou ${ }^{1,2}$, Supriya D Mehta ${ }^{3}$, Elizabeth Christian ${ }^{2}$, Brian Joyce ${ }^{1}$, Olufunmilayo \\ Lesi $^{4}$, Rose Anorlu ${ }^{5}$, Alani Sulaimon Akanmu ${ }^{6}$, Godwin Imade ${ }^{7}$, Edith Okeke ${ }^{7}$, Jonah \\ Musah $^{1,2,7}$, Firas Wehbe ${ }^{8}$, Jian-Jun Wei ${ }^{9}$, Demirkan Gursel ${ }^{9}$, Kate Klein ${ }^{2}$, Chad J \\ Achenbach $^{2,10}$, Ashti Doobay-Persaud ${ }^{2,11}$, Jane Holl2,13, Mamoudou Maiga ${ }^{2,14}$, Cheick \\ Traore $^{14}$, Atiene Sagay ${ }^{7}$, Folasade Ogunsola ${ }^{15}$, Robert Murphy ${ }^{2,10}$
}

\footnotetext{
${ }^{1}$ Department of Preventive Medicine, Division of Cancer Epidemiology and Prevention, Feinberg School of Medicine, Northwestern University, Chicago, Illinois, USA

${ }^{2}$ Institute for Global Health, Feinberg School of Medicine, Northwestern University, Chicago, Illinois, USA

${ }^{3}$ Division of Epidemiology and Biostatistics, School of Public Health, University of Illinois at Chicago, Chicago, Illinois, USA

${ }^{4}$ Department of Medicine, College of Medicine of the University of Lagos, Lagos, Nigeria

${ }^{5}$ Department of Obstetrics and Gynecology, College of Medicine, University of Lagos, Lagos, Nigeria

${ }^{6}$ Department of Haematology and Blood Transfusion, Lagos University Teaching Hospital, and College of Medicine of the University of Lagos, Lagos, Nigeria

${ }^{7}$ Department of Obstetrics and Gynecology, College of Health Sciences, University of Jos, Jos, Nigeria

${ }^{8}$ Department of Preventive Medicine, Division of Health and Biomedical Informatics, Feinberg School of Medicine, Northwestern University, Chicago, Illinois, USA

${ }^{9}$ Department of Pathology, Feinberg School of Medicine, Northwestern University, Chicago, Illinois, USA

${ }^{10}$ Division of Infectious Diseases, Department of Medicine, Feinberg School of Medicine, Northwestern University, Chicago, Illinois, USA

${ }^{11}$ Department of Medicine, Feinberg School of Medicine, Northwestern University, Chicago, Illinois, USA

${ }^{12}$ Biological Sciences Division, University of Chicago, Chicago, Illinois, USA

${ }^{13}$ School of Professional Studies, Northwestern University, Chicago, Illinois, USA

${ }^{14}$ University of Sciences, Techniques and Technologies of Bamako (USTTB), Bamako, Mali

${ }^{15}$ Department of Medical Microbiology, College of Medicine, University of Lagos, Lagos, Nigeria
}

S ince January 2020 billions of people across the world have been "locked down" and hundreds of thousands have died because of the COVID-19 global pandemic. The pandemic is creating enormous adverse economic and social consequences throughout the world, with direct and indirect impacts on global health activities - particularly through the participation of health care workers, clinicians, investigators, technologists, and students in research training and educational programs in low- and middle-income countries (LMICs).

Even as it has posed tremendous challenges to traditional models of training and education in global health settings, the COVID-19 pandemic has also led global health leaders to adapt and leverage new technologies and approaches to train and educate the next generation of scientists and educators.
A primary approach of global health training programs has been to bring trainees to grantee institutions in developed countries to participate in in-person coursework, attend skills-based workshops, and/or work directly with researchers and mentors. Another important component has been travel by mentors in the grantee institutions to partner institutions in LMICs to facilitate workshops, lectures, and in-person clinical investigation and laboratory trainings. Training has also consisted of participation in formal courses and degrees, with 
trainees completing either full-degree or certificate programs at universities, and/or working directly with their mentor. However, the near-complete shutdown of international travel prevents faculty, mentees, and mentors from taking part in these indispensable exchanges.

\section{CURRENT AND FUTURE CHALLENGES}

One of the largest institutions funding this type of education and training is the United States (US) National Institutes of Health (NIH) Fogarty International Center (FIC), dedicated to supporting and facilitating partnerships between health research institutions in the US and LMICs around the globe, and training scientists to address global health needs [1]. FIC has funded 153 global health training programs, including 118 programs that were active as of April 2020 [2]. FIC D43 training programs are funded through peer-reviewed grants and designed to be collaborative, long-term, and flexible to meet the research priorities of both the US and foreign institutions [2]. The training goals of a D43 program include short-, medium- and long-term goals. Short-term training goals are designed to be accomplished in less

\begin{abstract}
The widespread use of distance or virtual learning during the pandemic has highlighted both its advantages relative to traditional formats (eg, reduced expenses and increased capacity and flexibility with respect to audience and time) as well as its disadvantages (eg, in- person networking, interaction, and team building).
\end{abstract} than three months and are usually composed of faculty-led workshops or training sessions focused on specific areas of research methods or laboratory skills [3]. Medium-term training goals are designed to be accomplished over three to six months and include components such as working directly with a faculty mentor on a research project and taking non-degree courses to support specific research topics [3]. Long-term training goals are designed to be accomplished over a period of six months or more and can include formal graduate education such as master's, doctoral, and postdoctoral degree programs related to the training areas needed and public health concerns within trainees' home countries [3].

Table 1 provides information on strengths and weaknesses reflecting the impact that the COVID-19 pandemic may have on activities of global training programs based on our own experiences learned from our NIH FIC D43 training program in Nigeria and other global health educational programs. Short-term training activities previously had in-country, on-site components requiring travel by US faculty and mentors, which resulted in significant team-building and socio-cultural adoption. Due to COVID-19, travel is postponed or cancelled, replaced by shorter and more frequent virtual communications and lectures. This paradigm shift has resulted in lower program expenditures, more frequent contact between trainers and trainees, and allowed for the recruitment of a wider range of faculty for educational activities than would normally be feasible. Conversely, online interactions represent a loss of opportunity to expose mentees to other cultures and a diversity of ideas only available through international travel, including learning about different approaches to work and study methods, making new friends, starting networks poten-

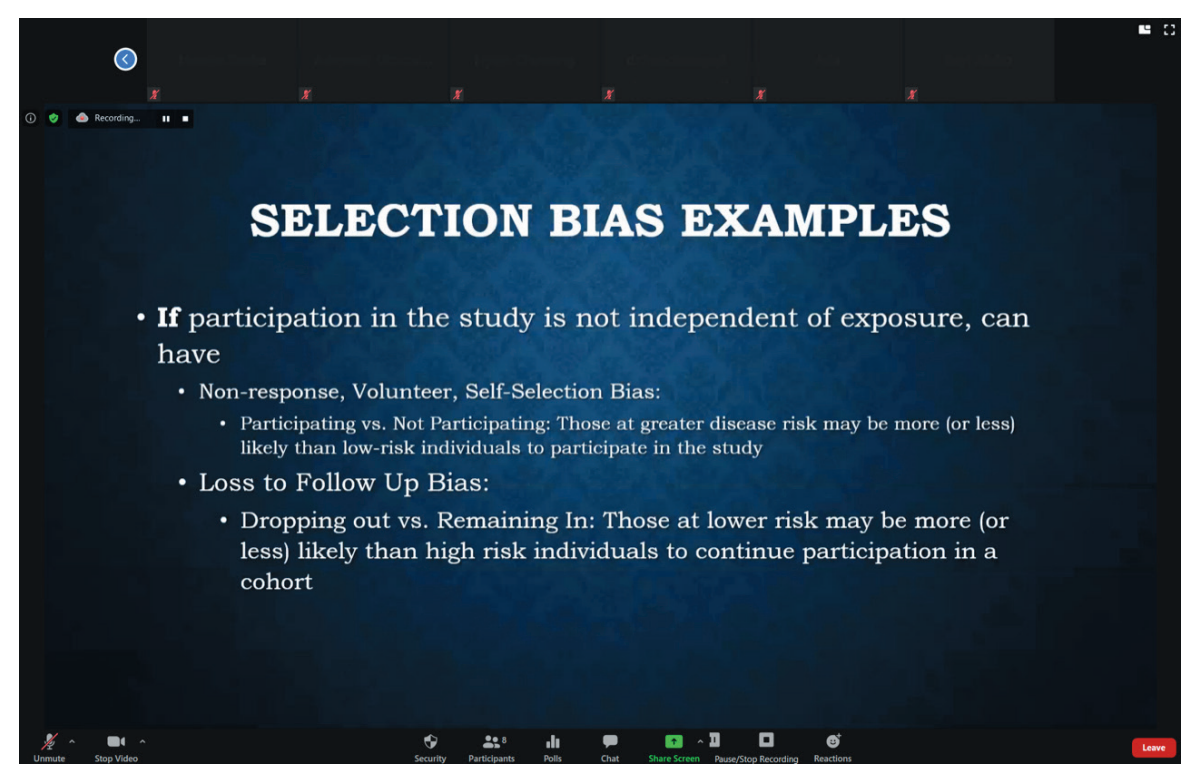

Photo: From the authors' own collection, used with permission. tially outside their original trainee study groups, and building global citizenship.

Medium-term training activities were often accomplished through a mix of in-person training in the US and LMICs. Trainees take part in specialized training with US-based faculty, with either party traveling, followed by in-country research. These medium-term training activities have similar weaknesses and strengths to the short-term training activities in response to the COVID-19 pandemic. For longer-term training activities, the COVID-19 pandemic is not projected to substantially impact in-country research and graduate training beyond the loss of travel for US and 
Table 1. Challenges and opportunities of global health training program due to COVID 19 pandemic*

\begin{tabular}{|c|c|c|c|c|c|}
\hline \multicolumn{3}{|l|}{ Pre-COVID-19 } & \multicolumn{3}{|l|}{ DuRING COVID-19 } \\
\hline $\begin{array}{l}\text { Planned } \\
\text { Activities }\end{array}$ & Weaknesses & Strengths & Adapted Activities & Weaknesses & Strengths \\
\hline \multicolumn{6}{|c|}{$\begin{array}{l}\text { Short-term training programs (0-3 months-duration): conferences/symposia, workshops, faculty enrichment; 1-3 } \\
\text { participants in the US, } 1-30 \text { in-country }\end{array}$} \\
\hline \multirow{4}{*}{$\begin{array}{l}\text { On-site } \\
\text { workshop } \\
\text { training }\end{array}$} & $\begin{array}{l}\text { Requirement of } \\
\text { travel }\end{array}$ & \multirow[t]{2}{*}{$\begin{array}{l}\text { Direct in-person } \\
\text { contact }\end{array}$} & \multirow{4}{*}{$\begin{array}{l}\text { Replaced by video } \\
\text { presentations and } \\
\text { discussions led by US } \\
\text { faculty }\end{array}$} & \multirow[t]{2}{*}{$\begin{array}{l}\text { Lack person-to- } \\
\text { person interactions }\end{array}$} & Expenses reduced \\
\hline & Costly & & & & $\begin{array}{l}\text { Able to spread out for more } \\
\text { contact over longer time }\end{array}$ \\
\hline & $\begin{array}{l}\text { Limited } \\
\text { frequencies }\end{array}$ & \multirow[t]{2}{*}{$\begin{array}{l}\text { Cross-institution } \\
\text { team building }\end{array}$} & & \multirow[t]{2}{*}{$\begin{array}{l}\text { Lack of experience } \\
\text { in US institute }\end{array}$} & \multirow{2}{*}{$\begin{array}{l}\text { Can source lectures from } \\
\text { more faculty without cost } \\
\text { barrier of travel }\end{array}$} \\
\hline & $\begin{array}{l}\text { Social-cultural } \\
\text { adoption }\end{array}$ & & & & \\
\hline \multirow{4}{*}{$\begin{array}{l}\text { On-site } \\
\text { annual } \\
\text { meeting }\end{array}$} & $\begin{array}{l}\text { Requirement of } \\
\text { travel }\end{array}$ & \multirow[t]{3}{*}{$\begin{array}{l}\text { Direct In-person } \\
\text { contact }\end{array}$} & \multirow[t]{4}{*}{$\begin{array}{l}\text { Replaced by video } \\
\text { meetings }\end{array}$} & \multirow[t]{2}{*}{$\begin{array}{l}\text { Lack person-to- } \\
\text { person interactions }\end{array}$} & \multirow[t]{3}{*}{ Expenses reduced } \\
\hline & Costly & & & & \\
\hline & $\begin{array}{l}\text { Limited } \\
\text { frequencies }\end{array}$ & & & \multirow{2}{*}{$\begin{array}{l}\text { Lack of experience } \\
\text { in conferences and } \\
\text { meetings }\end{array}$} & \\
\hline & $\begin{array}{l}\text { Social-cultural } \\
\text { adoption }\end{array}$ & $\begin{array}{l}\text { Cross-institution } \\
\text { team building }\end{array}$ & & & $\begin{array}{l}\text { More US and LMIC faculty } \\
\text { are able to join without cost } \\
\text { barrier of travel }\end{array}$ \\
\hline \multirow[t]{2}{*}{$\begin{array}{l}\text { Faculty } \\
\text { Enrichment }\end{array}$} & $\begin{array}{l}\text { Requirement of } \\
\text { travel }\end{array}$ & \multirow{2}{*}{$\begin{array}{l}\text { Cements } \\
\text { cross-institution } \\
\text { collaboration }\end{array}$} & \multirow[t]{2}{*}{ Postponed } & \multirow{2}{*}{$\begin{array}{l}\text { Rely on email and } \\
\text { other online } \\
\text { communications }\end{array}$} & \multirow[t]{2}{*}{ None } \\
\hline & Costly & & & & \\
\hline \multicolumn{6}{|c|}{ Medium term: specialized training (3-6 months) } \\
\hline \multirow{3}{*}{$\begin{array}{l}\text { Specialized } \\
\text { training }\end{array}$} & \multirow{2}{*}{$\begin{array}{l}\text { Requirement of } \\
\text { travel }\end{array}$} & \multirow{2}{*}{$\begin{array}{l}\text { Able to focus on } \\
\text { specific research } \\
\text { skills for } \\
\text { competencyD }\end{array}$} & \multirow{2}{*}{$\begin{array}{l}50 \% \text { of trainees } \\
\text { postponed }\end{array}$} & \multirow{3}{*}{$\begin{array}{l}\text { Loss of direct } \\
\text { contact with faculty }\end{array}$} & Expenses reduced \\
\hline & & & & & $\begin{array}{l}\text { Trainees joined virtual } \\
\text { lectures for increased } \\
\text { contact with US faculty }\end{array}$ \\
\hline & Costly & $\begin{array}{l}\text { irect In-person } \\
\text { contact }\end{array}$ & $\begin{array}{l}50 \% \text { of trainees were } \\
\text { able to participate in } \\
\text { online nondegree } \\
\text { training }\end{array}$ & & $\begin{array}{l}\text { More trainees able to join } \\
\text { virtual sessions }\end{array}$ \\
\hline \multicolumn{6}{|c|}{ Long Term: Graduate degree and non-degree training (>6 months) } \\
\hline \multirow{2}{*}{$\begin{array}{l}\text { Masters } \\
\text { (Non home } \\
\text { in-person) }\end{array}$} & $\begin{array}{l}\text { Social-cultural } \\
\text { adoption }\end{array}$ & \multirow{2}{*}{$\begin{array}{l}\text { Advanced } \\
\text { research training } \\
\text { in variety of } \\
\text { skills }\end{array}$} & $\begin{array}{l}\text { Trainees that already } \\
\text { started continued }\end{array}$ & $\begin{array}{l}\text { Loss of direct } \\
\text { contact with faculty }\end{array}$ & \multirow{2}{*}{$\begin{array}{l}\text { Expenses reduced for those } \\
\text { transitions online } \\
\text { Trainees joined virtual } \\
\text { lectures for increased } \\
\text { contact with US faculty }\end{array}$} \\
\hline & $\begin{array}{l}\text { Must set up LMIC } \\
\text { in-country } \\
\text { research from US }\end{array}$ & & $\begin{array}{l}\text { Trainees expected to } \\
\text { start were transitioned } \\
\text { to online per } \\
\text { university }\end{array}$ & $\begin{array}{l}\text { Loss of interaction } \\
\text { with other students }\end{array}$ & \\
\hline \multirow[t]{2}{*}{$\begin{array}{l}\text { Masters (US } \\
\text { online) }\end{array}$} & $\begin{array}{l}\text { Less direct } \\
\text { contact with US } \\
\text { faculty }\end{array}$ & $\begin{array}{l}\text { Advanced } \\
\text { research training } \\
\text { in variety of } \\
\text { skills }\end{array}$ & \multirow[t]{2}{*}{$\begin{array}{l}\text { Trainees continued as } \\
\text { university adjusted }\end{array}$} & \multirow[t]{2}{*}{ None } & $\begin{array}{l}\text { Trainees joined virtual } \\
\text { lectures for increased } \\
\text { contact with US faculty }\end{array}$ \\
\hline & & $\begin{array}{l}\text { Access to NU } \\
\text { online resource }\end{array}$ & & & \\
\hline $\begin{array}{l}\mathrm{PhD} \text { (US } \\
\text { in-person) }\end{array}$ & $\begin{array}{l}\text { Must set up LMIC } \\
\text { in-country }\end{array}$ & $\begin{array}{l}\text { Social-cultural } \\
\text { learning }\end{array}$ & $\begin{array}{l}\text { Trainees that already } \\
\text { started continued }\end{array}$ & $\begin{array}{l}\text { Loss of direct } \\
\text { contact with faculty }\end{array}$ & $\begin{array}{l}\text { Expenses reduced for those } \\
\text { transitions online }\end{array}$ \\
\hline & research from US & $\begin{array}{l}\text { Advanced } \\
\text { research training } \\
\text { in variety of } \\
\text { skills }\end{array}$ & & & \\
\hline & & $\begin{array}{l}\text { Access to NU } \\
\text { resources }\end{array}$ & $\begin{array}{l}\text { Trainees expected to } \\
\text { start were transitioned } \\
\text { to online per } \\
\text { university }\end{array}$ & $\begin{array}{l}\text { Loss of interaction } \\
\text { with other students }\end{array}$ & $\begin{array}{l}\text { Trainees joined virtual } \\
\text { lectures for increased } \\
\text { contact with US faculty }\end{array}$ \\
\hline
\end{tabular}

LIMC - low- and middle-income countries

* Based on Northwestern University Fogarty International Center (FIC) funded D43 global health training programs (full list of training grants can be found at https://www.globalhealth.northwestern.edu/centers/communicable-diseases/index.html and https:// www.globalhealth.northwestern.edu/centers/oncology/index.html) 
in-country partners and the delay in trainings that are absolutely needed in person. Many global health research training programs were already shifting online and can continue uninterrupted; traditional USbased graduate training is quickly catching up, with most already offering some online curriculum materials to trainees who are unable to travel to the US. While the COVID-19 pandemic may have a lasting impact on global health training and education, at the same time, these challenges can provide new opportunities.

\section{OPPORTUNITIES IN A POST-COVID WORLD}

The COVID-19 pandemic has forced global health research education and training program leaders and educators to consider and explore opportunities available through distance learning. Below, we give some examples from our programs that could hint at future transformations.

\section{Virtual education lectures}

Our own experience using a technological solution to replace traditional, in-person lectures has been well-received. A pilot presentation was set up for a US-based faculty member to give an introductory lecture on one of our project core competencies, cancer epidemiology. The lecture information and instructions to access and use the web-based video teleconferencing system were shared with two Nigerian subsites. In real time, attendees listened to the lecture, viewed the slides, and interacted with and provided feedback to the lecturer, facilitated by including defined opportunities for questions and discussion. To fully participate in the discussions, attendees had to ensure they had a secure internet connection. Conferencing etiquette skills such as muting of participants to preserve audio quality, use of hand-raising functions, and control of video view initially stifled open discussion but were rapidly adopted. Attendees expressed their enthusiasm for being able to attend in real time and having the opportunity to interact with the instructor. The lecture series has continued successfully as monthly sessions. Using remote lectures allowed mentors to connect with trainees at partner sites and accommodate more trainees, and enables lectures from more professors.

\section{Telemedicine approaches}

Traditionally, pathology training has been conducted under a microscope in a trainee's home institution. Under COVID-19 travel restrictions, we have been using digital or telepathology technologies to provide training sessions to our pathologist trainees. Pathological slides are translated into digital or virtual images using an image scanner and shared by mentors and mentees from a desktop/laptop computer without restrictions to geographic location with no loss of information. The image can be stored in a cloud and accessed and reviewed any time by both mentors and mentees, at the same time, with no additional laboratory equipment. Similar approaches can be used in other medical training programs, such as digital radiology and other telemedicine.

\section{Molecular laboratory training and education}

The training of molecular laboratory scientists has largely been conducted in local laboratories, or by bringing trainees to the host institution(s). Since the COVID-19 outbreak, we have used virtual and digital technologies to train molecular laboratory trainees at our partner universities in Nigeria in both theoretical and practical perspectives with excellent feedback and promising results. These virtual approaches enable us to streamline the complicated tasks common to molecular laboratories such as development and implementation of protocols and quality control (QC) procedures, sample collection and processing, inventory and tracking, data entry, and load balancing. Such virtual cross-talk allows mentors and mentees to connect via video, and allows the mentees to see each protocol step in detail regardless of geographic proximity.

\section{Training health care providers}

Before the COVID-19 pandemic, Northwestern University and the University of Lagos in Nigeria had been planning a user-centered palliative care training program for health care professionals without formal training in Nigeria. We initially planned a 2-day on-site workshop leveraging the previously implemented content from the EPEC (Education in Palliative and End-of- Life Care) program[4] which trains physicians, nurses, and other health care professionals in fundamental palliative care skills in communi- 
cation, ethical decision-making, psychosocial considerations, and symptom management. Because of the COVID-19 pandemic, we have redesigned the curriculum and workshops. Lecture, video, role plays, and small group discussions will be held virtually. To enhance the interactions between trainees and mentors, we use breakout room features for small group discussion and chat functions to support interactive question and answer periods. Other online apps or interactive software for polling, whiteboard, and extension technology functions are also adopted to enhance the interactions.

As shown by these examples, the COVID-19 pandemic has transformed global health training and educational programs. While virtual approaches can be effective at lower cost, they may also have deleterious effects on trainees' mentorship and professional development as a result of weakened or lost in-person interactions, team building, socio-cultural adoption and understanding, and interpersonal relationships [5]. Given the altered formats and timelines of training as demonstrated in Table 1 and the possibility of long-term adoption of these changes, future programs may attract different types of learners with different and varied motivations, expectations, and outcomes [6]. The development of new "hybrid" models using proven virtual components but with built-in, in-person activities better suited to discussion, idea generation, and team and relationship building may provide the best approaches for global health training and education in the post COVID-19 era.

\footnotetext{
Funding: Research reported in this publication was supported by the Fogarty International Center of the Nation-
al Institutes of Health under award numbers D43TW009575, D43TW010350, D43TW01034, D43TW010130,
D43TW10140, U54CA221205. EPEC curriculum adaptation and training is supported the Northwestern Univer-
sity Global Health Initiative at the Institute for Global Health, which is generously supported by Northwestern
Medicine Primary and Specialty Care.
Authorship contributions: LH and RM conceptualized the article. EC conducted data collection and background
research. All authors contributed to data interpretation and manuscript writing equally.
Competing interests: The authors completed the ICMJE Unified Competing Interest form (available upon request
from the corresponding author), and declare no conflicts of interest.
}

1 Fogarty International Center. Available: https://www.fic.nih.gov/About/Pages/mission-vision.aspx. Accessed: 22 May 2020.

2 Fogarty at 50: Advancing science for global health since 1968. Available: https://www.fic.nih.gov/About/50th-anniversary/ Documents/fogarty-international-center-nih-at-50.pdf. Accessed: 22 May 2020.

3 Global Infectious Disease Research Training - Fogarty International Center @ NIH. Available: https://www.fic.nih.gov/Programs/Pages/infectious-disease.aspx. Accessed: 22 May 2020.

4 Hauser JM, Preodor M, Roman E, Jarvis DM, Emanuel L. The Evolution and Dissemination of the Education in Palliative and End-of-Life Care Program. J Palliat Med. 2015;18:765-70. Medline:26302426 doi:10.1089/jpm.2014.0396

5 Wanberg CR, Welsh ET, Hezlett SA. Mentoring research: A review and dynamic process model. Research in Personnel and Human Resources Management. 2003;22:39-124. doi:10.1016/S0742-7301(03)22002-8

6 Wang C-H, Shannon DM, Ross ME. Students' characteristics, self-regulated learning, technology self-efficacy, and course outcomes in online learning. Distance Educ. 2013;34:302-23. doi:10.1080/01587919.2013.835779

\author{
Correspondence to: \\ Lifang Hou, MD, PhD \\ 680 N Lake Shore Drive \\ Ste 1400 \\ Chicago IL 60611 \\ USA \\ 1-hou@northwestern.edu \\ Robert Murphy, MD \\ 710 N Lake Shore Drive \\ Ste 800 \\ Chicago IL 60611 \\ USA \\ r-murphy@northwestern.edu
}

